\title{
Determining the temporal variability in atmospheric temperature profiles measured using radiosondes and assessment of correction factors for different launch schedules
}

\author{
D. Butterfield and T. Gardiner \\ National Physical Laboratory, Hampton Road, Teddington, Middlesex, TW11 0LW, UK \\ Correspondence to: D. Butterfield (david.butterfield@npl.co.uk) and T. Gardiner (tom.gardiner@npl.co.uk) \\ Received: 2 July 2014 - Published in Atmos. Meas. Tech. Discuss.: 12 August 2014 \\ Revised: 18 November 2014 - Accepted: 16 December 2014 - Published: 29 January 2015
}

\begin{abstract}
Radiosondes provide one of the primary sources of upper troposphere and stratosphere temperature data for numerical weather prediction, the assessment of long-term trends in atmospheric temperature, study of atmospheric processes and provide intercomparison data for other temperature sensors, e.g. satellites. When intercomparing different temperature profiles it is important to include the effect of temporal mismatch between the measurements. To help quantify this uncertainty the atmospheric temperature variation through the day needs to be assessed, so that a correction and uncertainty for time difference can be calculated. Temperature data from an intensive radiosonde campaign, at Manus Island in Papua New Guinea, were analysed to calculate the hourly rate of change in temperature at different altitudes and provide recommendations and correction factors for different launch schedules. Using these results, three additional longer term data sets were analysed (Lindenberg 1999 to 2008; Lindenberg 2009 to 2012; and Southern Great Plains 2006 to 2012) to assess the diurnal variability of temperature as a function of altitude, time of day and season of the year. This provides the appropriate estimation of temperature differences for given temporal separation and the uncertainty associated with them. A general observation was that 10 or more repeat measurements would be required to get a standard error of the mean of less than $0.1 \mathrm{~K}$ per hour of temporal mismatch.
\end{abstract}

\section{Introduction}

Radiosondes provide one of the primary sources of upper troposphere and stratosphere temperature data for numerical weather prediction, the assessment of long-term trends in atmospheric temperature, study of atmospheric processes and provide intercomparison data for other temperature sensors, e.g. satellites. For many of these applications, understanding the measurement uncertainty is crucial to effectively using the data and interpreting the relationship between different measurement sources. The Global Climate Observing System (GCOS) and the Reference Upper Air Network (GRUAN) have been established under the joint auspices of GCOS and relevant commissions of the World Meteorological Organization (WMO) as an international reference observing network, designed to meet climate requirements and to fill a large gap in the current global observing system (Thorne et al., 2013). Extensive work has been undertaken within GRUAN to establish the traceable measurement uncertainty associated with radiosonde measurements (Immler et al., 2010). However, when comparing profile results between different atmospheric sensors, the individual sensor measurement uncertainties only make up part of the overall comparison uncertainty. Allowance also has to be made for the coincidence uncertainty in time and space, and the smoothing uncertainty in the two profile measurements (von Clarmann, 2006). This paper addresses the coincidence uncertainty associated with using radiosonde results for intercomparisons with other temperature measurements.

Intercomparisons between temperature measurements made by radiosondes and satellites are well documented (Free and Seidel, 2005; Randel et al., 2009). The perfor- 
mance of radiosonde temperature sensors is reasonably well understood and these sensors are normally traceably calibrated on site before launch (Immler et al., 2010). Whereas satellite sensors are well characterised and calibrated before launch (Mo, 1996), there is no direct mechanism to validate this calibration post-launch or over the time history of the satellite's mission. Drift corrections can be performed (Zou and Wang, 2010) and agreements with other satellite measurement methods calculated (Zou et al., 2014), however these do not make a direct comparison with actual in-atmosphere temperature measurements. Regular intercomparisons between satellite and radiosonde measurements need to be performed to validate the ongoing temperature calibration of the satellite. Arranging a coincident satellite overpass of a radiosonde launch is difficult and in most cases impractical. Therefore the rate of change in atmospheric temperature needs to be assessed and an appropriate launch schedule determined to allow valid comparisons. Previous work (Sun et al., 2010) has found that the mean temperature difference (all altitudes) across 13 types of radiosonde and the Constellation Observing System for Meteorology, Ionosphere and Climate (COSMIC) Global Positioning System, Remote Occultation (GPS RO) satellite measurements for a global network to be $0.15 \mathrm{~K}$. For Vaisala radiosondes, whose data was analysed in this paper, an increasing warm bias (from 0-0.4 K) with altitudes above $19 \mathrm{~km}(50 \mathrm{hPa})$ was found. The effect of the difference in radiosonde launch time and satellite overpass was also examined. The comparison standard deviation errors (all radiosonde types) for temperature were found to be $0.35 \mathrm{~K}$ per $3 \mathrm{~h}$ time difference.

The aim of this paper is to establish a methodology, from the limited data available from sites with a high launch frequency, to see if a data correction factor could be established at these sites to guide launch schedules. This represents the first step in developing a general tool for calculating temporal correction factors for any ground-based monitoring site. This work presents the results of a study of existing radiosonde data sets in order to estimate the uncertainty that would arise due to a temporal mismatch between a radiosonde profile and another source of temperature data. This is derived as a function of altitude, time of day and season of the year. This paper does not try to physically explain or quantify the reasons behind the correction factors derived at each site. In addition to providing an estimation of the coincidence uncertainty in time, it also gives guidance on the frequency of radiosonde launches required to capture diurnal variations.

\section{Overview and data}

To help quantify the difference between radiosonde and satellite measurements the diurnal atmospheric temperature variation needs to be assessed, so that a correction for time difference can be calculated. Radiosondes are routinely launched at 12-hourly intervals (00:00 and 12:00 UTC) from

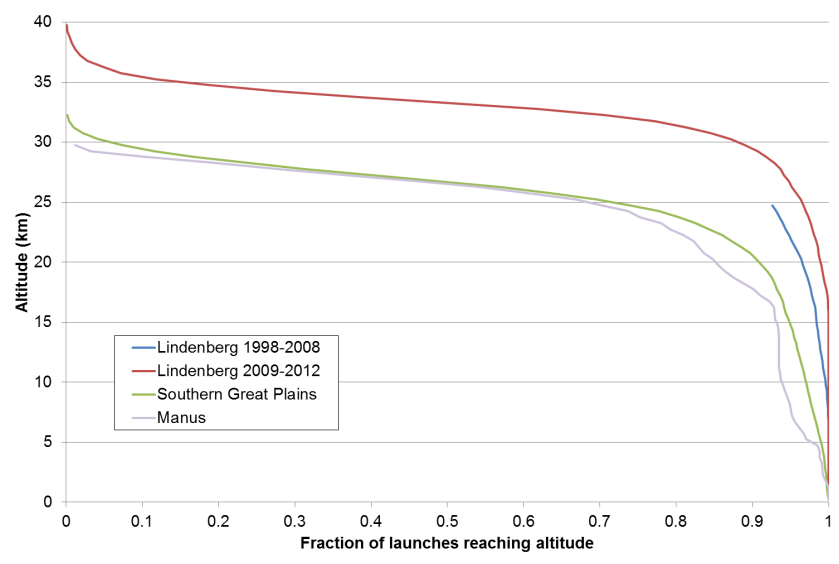

Figure 1. Fraction of radiosonde launches providing results as a function of altitude for each data set used. Blue line: Lindenberg 1999 to 2008; red line: Lindenberg 2009 to 2012; green line: Southern Great Plains; grey line: Manus Island.

many sites around the globe (Seidel and Free, 2006) with a very limited number of sites making more frequent measurements (WMO, 2013). To determine the frequency of launches needed to have an acceptable understanding of the atmosphere's temperature stability over short time periods $(<24 \mathrm{~h})$, temperature measurements from radiosonde flights made by the upper-air sounding network for Dynamics of the Madden-Julian Oscillation (DYNAMO) at Manus Island, Papua New Guinea were analysed. During this campaign, Vaisala RS92-SGP radiosondes with GPS wind finding were launched every $3 \mathrm{~h}$ (00:00, 03:00, 06:00, 09:00, 12:00, 15:00, 18:00, 21:00 UTC) from 24 September 2011 to 31 March 2012. After conversion to local time, the hourly rate of change in temperature between launches was calculated for $500 \mathrm{~m}$ altitude bins from the surface to $24 \mathrm{~km}$, for launches 3, 6 and $12 \mathrm{~h}$ apart. The mean hourly rates of change were inter-compared to assess the launch frequency required to acceptably characterise the diurnal change in temperature.

Following the analysis of launch frequency, long-term data from four radiosonde launches per day at Lindenberg (1999 to 2008 Vaisala RS90 radiosonde and 2009 to 2012 Vaisala RS92-SGP radiosonde) in Southern Germany and Southern Great Plains (Vaisala RS92 radiosonde 2006 to 2012) Oklahoma, USA were analysed to give hourly rates of change in temperature. Table 1 gives a summary of the radiosonde data sets.

The rate of change data was analysed to show differences in temperature stability between launches over a $24 \mathrm{~h}$ period and over the four seasons of the year, again up to an altitude of $24 \mathrm{~km}$. Although some results were available up to $40 \mathrm{~km}$, the number of samples fell off significantly with altitude as shown in Fig. 1. The maximum altitude of $24 \mathrm{~km}$ was selected as a suitable upper limit as all data sets giving $>75 \%$ data capture rates up to this altitude. 
Table 1. Summary of radiosonde data sets used.

\begin{tabular}{lllll}
\hline Launch site & Manus & Lindenberg & Lindenberg & Southern Great Plains \\
\hline Latitude & $2^{\circ} 3^{\prime} 39.64^{\prime \prime} \mathrm{S}$ & $52^{\circ} 12^{\prime} 36.0^{\prime \prime} \mathrm{N}$ & $52^{\circ} 12^{\prime} 36.0^{\prime \prime} \mathrm{N}$ & $36^{\circ} 36^{\prime} 18.0^{\prime \prime} \mathrm{N}$ \\
Longitude & $147^{\circ} 25^{\prime} 31.43^{\prime \prime} \mathrm{E}$ & $14^{\circ} 7^{\prime} 12.0^{\prime \prime} \mathrm{E}$ & $14^{\circ} 7^{\prime} 12.0^{\prime \prime} \mathrm{E}$ & $97^{\circ} 29^{\prime} 6.0^{\prime \prime} \mathrm{W}$ \\
Start & $24 / 09 / 2011$ & $01 / 01 / 1999$ & $01 / 01 / 2009$ & $01 / 01 / 2006$ \\
End & $31 / 03 / 2012$ & $31 / 12 / 2008$ & $31 / 12 / 2012$ & $31 / 12 / 2012$ \\
Launches per day & 8 & 4 & 4 & 4 \\
Sonde & RS92-SGP & RS90 & RS92-SGP & RS92-SGP \\
Total number of launches & 1002 & 14466 & 4555 & 9754 \\
$\begin{array}{l}\text { Median near surface } \\
\left(0 \text { to 500 m) temperature, }{ }^{\circ} \mathrm{C}\right.\end{array}$ & 26.4 & 9.4 & & 17.1 \\
$\begin{array}{l}\text { Minimum daily near surface } \\
\left(0 \text { to } 500 \mathrm{~m} \text { ) temperature, }{ }^{\circ} \mathrm{C}\right.\end{array}$ & 15.9 & -17.6 & & -14.3 \\
Maximum daily near surface & 34.3 & & & 40.9 \\
$\left(0\right.$ to 500 m) temperature, ${ }^{\circ} \mathrm{C}$ & & 30.2 & & \\
\hline
\end{tabular}

\section{Results and discussion}

\subsection{Manus Island DYNAMO data set}

Radiosonde temperature readings are amalgamated into altitude bins $500 \mathrm{~m}$ high, labelled as the centre of each bin, i.e. 0 to $500 \mathrm{~m}$ labelled as $250 \mathrm{~m}$. The temperatures in each altitude bin are averaged to provide a mean temperature, $T$, for that specific altitude. The rate of change in temperature between single launches 3, 6 and $12 \mathrm{~h}$ apart, at each altitude, were calculated according to Eq. (1). The mean rate of change in temperature between each launch separation and altitude, $\frac{\mathrm{d} T}{\mathrm{~d} t_{n}}$, were then calculated according to Eq. (2):

$\frac{\mathrm{d} T}{\mathrm{~d} t_{n}}=\frac{T_{n}-T_{0}}{t_{n}-t_{0}}$

where $n=3,6$, or 12 h separation between launch time;

$$
\frac{\overline{\mathrm{d} T}}{\mathrm{~d} t_{n}}=\frac{\sum \frac{\mathrm{d} T}{\mathrm{~d} t_{n}}}{i}
$$

where $i=$ the number of launch pairs.

The mean rates of change in temperature $\left(\frac{\mathrm{d} T}{\mathrm{~d} t_{3}}, \frac{\mathrm{d} T}{\mathrm{~d} t_{6}}\right.$ and $\left.\frac{\mathrm{d} T}{\mathrm{~d} t_{12}}\right)$ were used to define temperature change profiles over the day at different altitudes and are shown in Fig. 2. These profiles are for the complete 6-month data set and have not been split into seasons.

The times given in the figure show the mid-point in local time (LT) between the two launches used to calculate the temperature differences. Note that, for the $12 \mathrm{~h}$ separation results the launch times used are the 00:00 and 12:00 UTC radiosonde launches that are typically used by sites carrying out two launches per day. The error bars on the profiles come from the standard error of the mean. It can be seen in Fig. 2 that the profiles from launches 3 and $6 \mathrm{~h}$ apart follow similar profiles during the day, within the error bars (standard error of the mean), while the profiles from launches $12 \mathrm{~h}$ apart are unrepresentative and generally underestimate the actual diurnal variability. The profiles shown in Fig. 2 are a subset of all the altitudes evaluated. The complete set can be viewed online in the Supplement.

In order to quantify the difference between the different launch schedules it was assumed that 8 launches per day provided the best available measure of the changing state of the atmosphere. The mean hourly rates of change in temperature from these launches were therefore considered to be the base set. The difference in temperature change rates, $\Delta \frac{\overline{\mathrm{d} T}}{\mathrm{~d} t_{n}}\left(\mathrm{~K} \mathrm{~h}^{-1}\right)$ between the base set and a single launch, 2 launches a day and 4 launches a day were calculated according to Eq. (3). The results of which can be seen in Fig. 3:

$\Delta \frac{\overline{\mathrm{d} T}}{\mathrm{~d} t_{n}}=\frac{\sum \mathrm{ABS}\left(\overline{\frac{\mathrm{d} T}{\mathrm{~d} t_{n}}}-\overline{\mathrm{d} T} \frac{\overline{\mathrm{d} t_{3}}}{\mathrm{C}_{2}}\right)}{8}$

where $n=6$ or 12 . For single launches, $\Delta \frac{\overline{\mathrm{d} T}}{\mathrm{~d} t_{n}}$ was taken as the mean of $\frac{\overline{\mathrm{d} T}}{\mathrm{~d} t_{3}}$.

It can be seen from Fig. 3 that there is a marked difference in the temperature change rate between 4 launches a day and 2 launches a day, and that there is little improvement in performing 2 launches a day over a single launch. The 4 launches per day data set is statistically different from the single launch data set at all altitudes except $3250 \mathrm{~m}$, with a confidence level of $1 \sigma(68 \%)$. At the $2 \sigma(95 \%)$ level, three altitudes $(9250,12250$ and $15250 \mathrm{~m})$ are statistically different. It is therefore assumed in the later analyses that launches spaced $6 \mathrm{~h}$ apart provide a reasonable estimation of the hourly rate of change in temperature. Launches spaced $12 \mathrm{~h}$ apart do not suitably follow the short-term variations in temperature change over a $24 \mathrm{~h}$ period. Clearly this result only directly applies to the Manus data set, but it provides reasonable confidence in the use of 4 launches per day data for longer term analysis. 


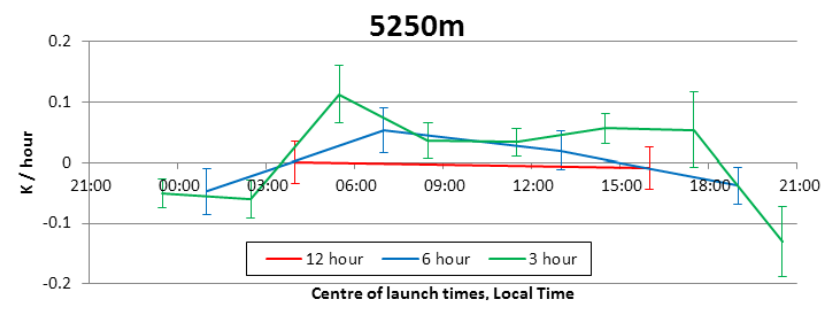

$9250 \mathrm{~m}$

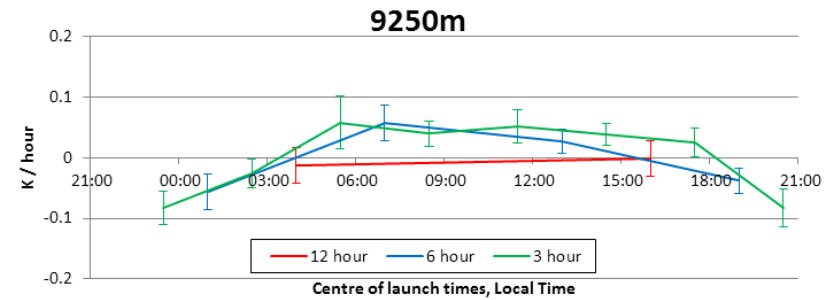

$12250 \mathrm{~m}$

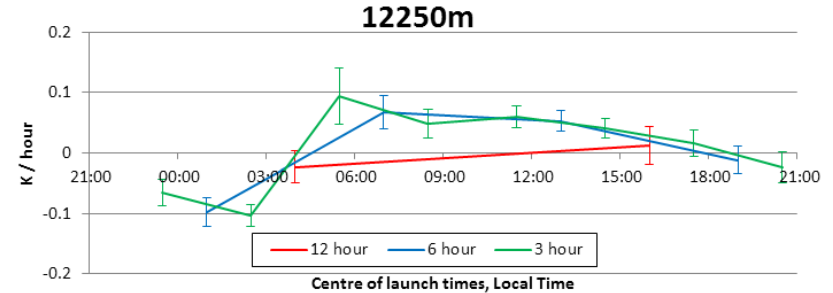

$15250 \mathrm{~m}$

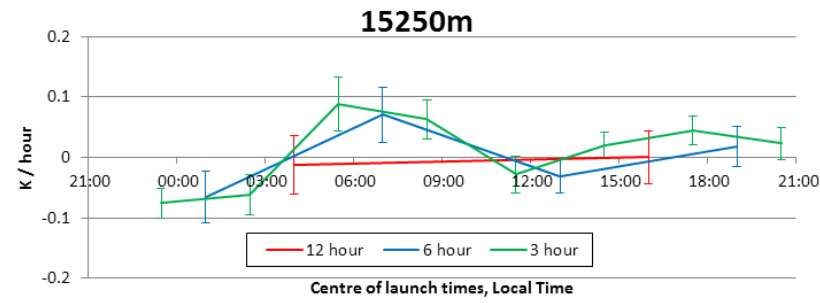

$18250 m$

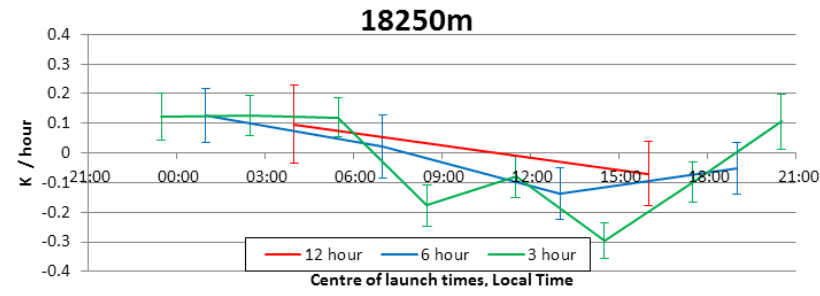

21250m

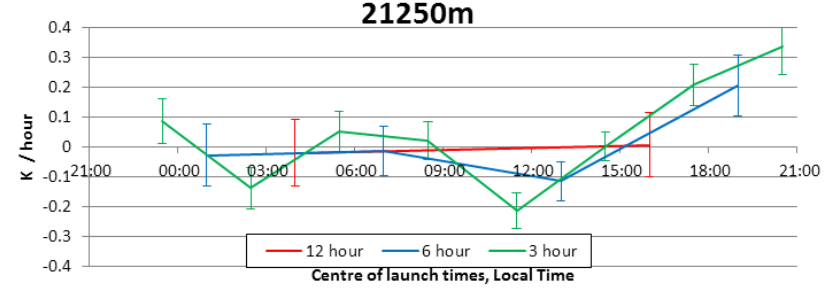

Figure 2. The $24 \mathrm{~h}$ profiles of mean temperature change rate from radiosonde launches at Manus Island during the DYNAMO campaign. Error bars are the standard error of the mean. Red line: $12 \mathrm{~h}$ separation; blue line: $6 \mathrm{~h}$ separation; green line: $3 \mathrm{~h}$ separation.

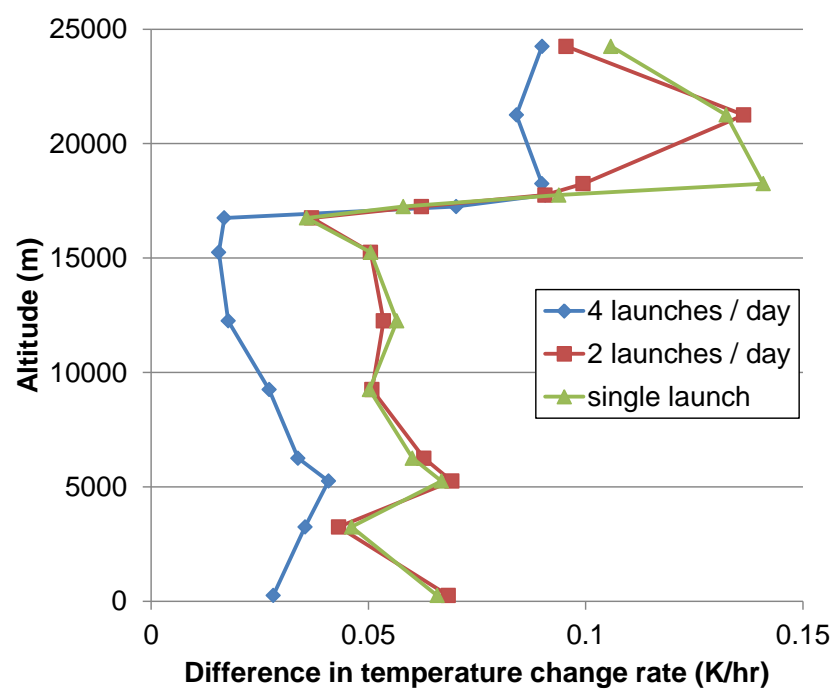

Figure 3. Difference in temperature change rate for a single launch (green triangles), 2 launches a day (red squares) and 4 launches a day (blue diamonds).

\subsection{Lindenberg and Southern Great Plains data sets}

Once a $6 \mathrm{~h}$ launch frequency was accepted to adequately represent the rate of change in temperature, three data sets were processed to calculate hourly rates of change, according to Eq. (2), between the four launches covering a $24 \mathrm{~h}$ period. Each data set was broken down into seasons and the calculations repeated to show if there were any changes in behaviour. Subsets of these results are shown in Figs. 4 and 5. Plots for all launches across all seasons can be viewed online in the Supplement. The error bars represent the standard error of the mean. Note that, as with the Manus data, the launches spaced $12 \mathrm{~h}$ apart (at 00:00 and 12:00 UTC) did not show the same degree of diurnal variability as the $6 \mathrm{~h}$ launch results.

It can be seen from Fig. 4 that all three data sets show similar behaviour for all launches during winter, except for the Lindenberg 1999-2008 data set, which shows some divergence in the stratosphere for the rate of change calculated from the 12:00 and 18:00 local time launches. Figure 5 shows the results for all four seasons of the rate of change calculated from the 12:00 and 18:00 local time launches. In addition to the winter divergence highlighted earlier, the Southern Great Plains (SGP) data set shows cooling in the stratosphere in spring, while the two Lindenberg data sets show heating. SGP shows significantly more heating in the troposphere and above $22 \mathrm{~km}$ in the summer. Autumn SGP results are also significantly different from Lindenberg in the lower troposphere, while the two Lindenberg data sets diverge in the stratosphere and are split by the SGP data set at this altitude. Summaries of near surface temperature $(0-500 \mathrm{~m})$ are given in Table 1 to give an indication of the local climate during the radiosonde launches. This difference in the stratosphere in the Lindenberg data may be due to the changes 


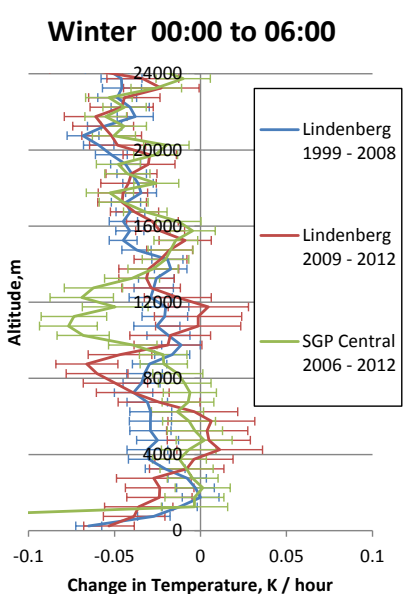

Winter $12: 00$ to $18: 00$

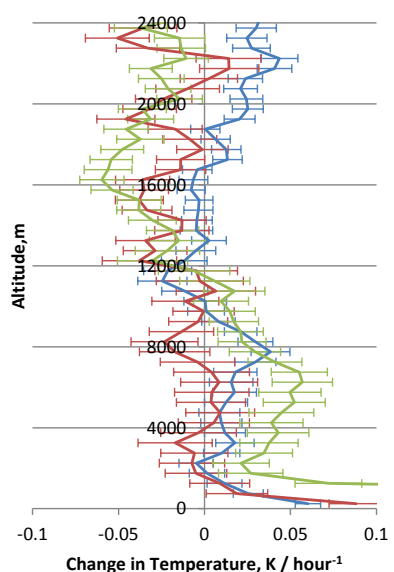

Winter 06:00 to $12: 00$

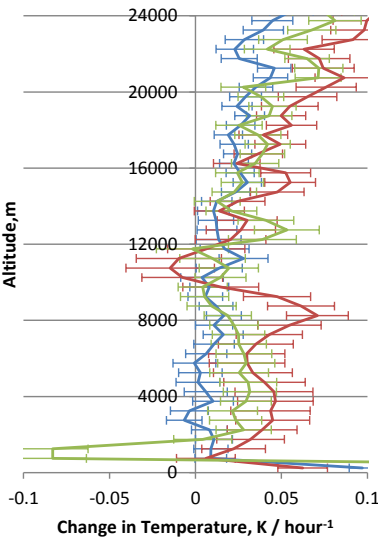

Winter 18:00 to 00:00

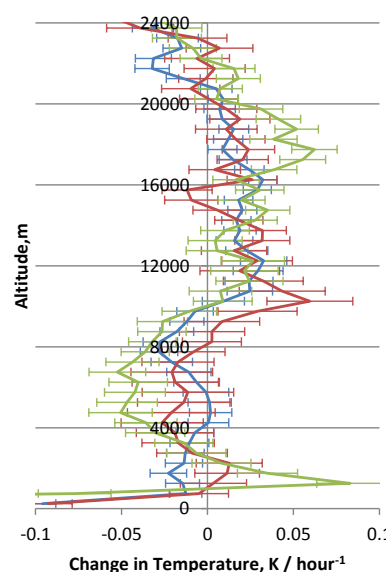

Figure 4. Hourly temperature change rate from 0 to $24 \mathrm{~km}$, for the three data sets during winter. Blue line: Lindenberg 1999 to 2008; red line: Lindenberg 2009 to 2012; green line: Southern Great Plains.

in radiosonde type and analysis procedures between the two data sets. The influence of these changes and the effect of improved knowledge of the measurement uncertainty in the more recent data is a potential area for further investigation.

The error bars in Figs. 4 and 5 are expressed as the standard error of the mean result. If the standard deviation for a complete data is calculated and then the standard error calculated for differing numbers of repeat measurements, this gives an indication of the number of repeat measurements/radiosonde flights with corresponding satellite overpasses that would need to be made to bring the uncertainty in the temperature correction into acceptable bounds. Table 2 gives a summary of the mean temperature change rate between two launch times $6 \mathrm{~h}$ apart from a single data set (Lindenberg 1999 to 2008) along with the standard deviation of the measurements, the standard error of the mean for 10 and 100 repeated measurements for the four seasons of the
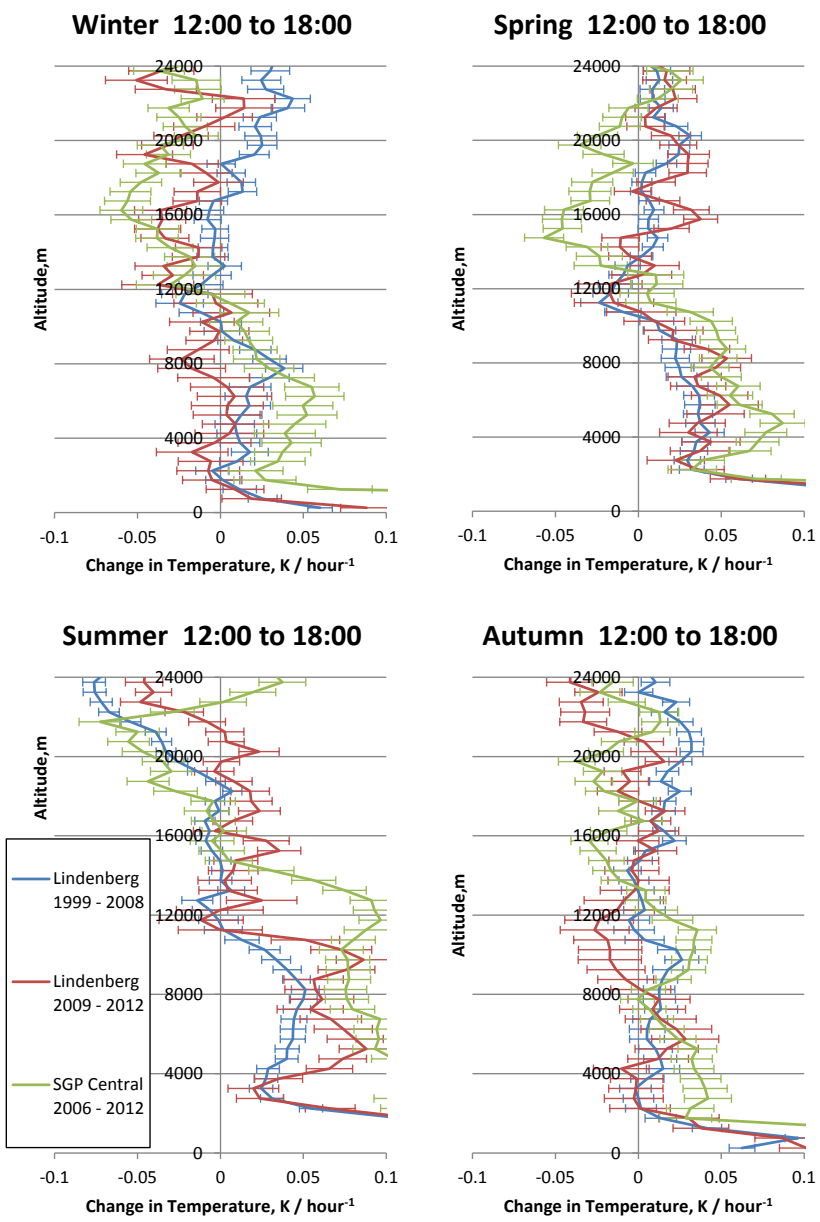

Figure 5. Hourly temperature change rate from 0 to $24 \mathrm{~km}$, for three data sets, calculated from launches at 12:00 and 18:00 local time for all four seasons. Blue line: Lindenberg 1999 to 2008; red line: Lindenberg 2009 to 2012; green line: Southern Great Plains.

year. The results for the three data sets for all seasons can be viewed online in the Supplement.

Figure 6 summarises the results at $5 \mathrm{~km}$ altitude in spring for 13:00 and 19:00 local time, to give an indication of the reduction in the uncertainty with increased number of measurements for each data set. It can be seen that to obtain a standard error of the mean rate of change in temperature of $<=0.1 \mathrm{~K}$ per hour, 10 or more repeat measurements are required. The standard errors of the means for 100 measurements in Table 2 are similar to those for the Manus Island results in Fig. 2 (0.038), which were typically made up of 90 launches per result. The number of launches per data point for the Lindenberg 1999 to 2008 data set is 889 , for the Lindenberg 2009 to 2012 data set 227 and 572 for the Southern Great Plains data set.

The data in Fig. 6 also shows how these results could be used in practice. Taking the Lindenberg 1999 to 2008 results as an example, if a comparison was made between a single SGP radiosonde temperature measurement and another tem- 
Table 2. Lindenberg 1999-2008. Mean rate of change in temperature between launches at 13:00 and 19:00 local time at different altitudes for each season, along with standard deviation of a single measurement and standard error with increased number of measurements.

\begin{tabular}{lrrrr}
\hline Altitude $5 \mathrm{~km}$ & Spring & Summer & Autumn & Winter \\
\hline Mean rate of change, $\mathrm{K} \mathrm{h}^{-1}$ & 0.036 & 0.040 & 0.010 & 0.013 \\
SD $(1$ reading) & 0.265 & 0.219 & 0.304 & 0.372 \\
SE (10 readings) & 0.084 & 0.069 & 0.096 & 0.118 \\
SE (100 readings) & 0.026 & 0.022 & 0.030 & 0.037 \\
\hline Altitude $10 \mathrm{~km}$ & Spring & Summer & Autumn & Winter \\
\hline Mean rate of change, $\mathrm{K} \mathrm{h}^{-1}$ & 0.011 & 0.027 & 0.023 & 0.000 \\
SD $(1$ reading) & 0.305 & 0.280 & 0.337 & 0.368 \\
SE $(10$ readings) & 0.097 & 0.088 & 0.107 & 0.116 \\
SE (100 readings) & 0.031 & 0.028 & 0.034 & 0.037 \\
\hline Altitude $15 \mathrm{~km}$ & Spring & Summer & Autumn & Winter \\
\hline Mean rate of change, $\mathrm{K} \mathrm{h}^{-1}$ & 0.006 & -0.005 & 0.004 & -0.003 \\
SD $(1$ reading) & 0.182 & 0.191 & 0.215 & 0.235 \\
SE (10 readings) & 0.058 & 0.060 & 0.068 & 0.074 \\
SE (100 readings) & 0.018 & 0.019 & 0.021 & 0.023 \\
\hline Altitude $20 \mathrm{~km}$ & Spring & Summer & Autumn & Winter \\
\hline Mean rate of change, $\mathrm{K} \mathrm{h}^{-1}$ & 0.031 & -0.033 & 0.032 & 0.024 \\
SD $(1$ reading) & 0.199 & 0.175 & 0.202 & 0.270 \\
SE (10 readings) & 0.063 & 0.055 & 0.064 & 0.085 \\
SE (100 readings) & 0.020 & 0.017 & 0.020 & 0.027 \\
\hline
\end{tabular}

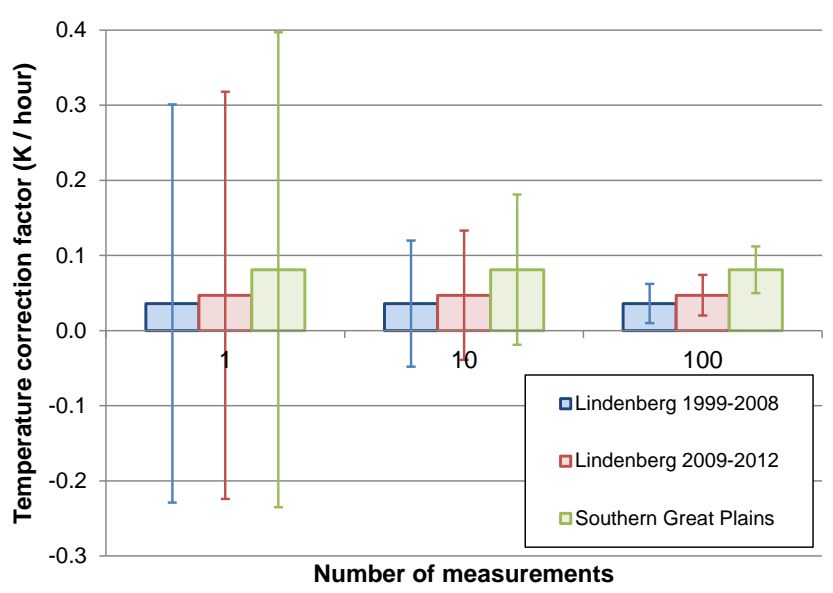

Figure 6. Reduction in uncertainty in hourly temperature change rate due to repeat radiosonde flights - for measurements between 13:00 and 19:00 LT, at 5km altitude in spring. Columns show the mean temperature change rate and error bars should the uncertainty associated with different numbers of samples. Blue: Lindenberg 1999 to 2008; red: Lindenberg 2009 to 2012; green: Southern Great Plains.

perature measurement (between 13:00 and 19:00 local time, at $5 \mathrm{~km}$, in spring) then for each hour difference between the measurements a correction of $0.036 \mathrm{~K}$ should be applied to the radiosonde result and an additional random uncertainty of
$0.265 \mathrm{~K}$ should be included in the comparison. This correction should be subtracted from the radiosonde measurement to adjust for the temporal mismatch. If this was repeated 10 times the correction factor would remain the same, but the additional random uncertainty would reduce to $0.084 \mathrm{~K}$. The supplementary data gives a summary of results for all three data sets over the separate $6 \mathrm{~h}$ launch separations. The results enable such an evaluation to be made for any altitude, time of day and season.

\section{Conclusions and further work}

Four radiosonde data sets have been analysed to assess the temporal variability of the temperature profile as a function of altitude, time of day and season of the year. This provides information on the temporal mismatch uncertainty that would result from comparing atmospheric temperature measurements at different times. The results from the intensive Manus campaign with 8 launches per day show that 2 radiosonde launches per day (at 00:00 and 12:00 UTC) do not capture the diurnal variability and would tend to underestimate both the adjustment and uncertainty that would result from a temporal mismatch, but that 4 radiosonde launches per day provides a reasonable estimate of the diurnal variability.

Analysis of longer term data sets with four launches per day provide appropriate estimation of temperature differ- 
ences for a given temperature separation and the uncertainties associated with them. The uncertainties show similar behaviour for all data sets and indicate that, in general, 10 or more repeat measurements would be required to get a standard uncertainty of less than $0.1 \mathrm{~K}$ per hour of temporal mismatch.

Having established that the method presented in this paper is a viable one for estimating temporal variability, it should be recognised that these results only directly apply to the radiosonde launch sites from which the data sets have been obtained. In order to generate appropriate correction factors for other sites the method will require further development, using additional data sources or model results for each site.

Given the conclusion that at least four launches per day are needed to capture the diurnal variability and the very limited number of launch sites from which such long term data is available, then a modification to this analysis would be needed to give it wider global applicability. Two methods to consider are combining twice daily radiosonde results with higher temporal resolution data from another measurement technique or using high resolution meteorological models to fill in the gaps between the radiosonde launches. Both options will be the subject of further work.

\section{The Supplement related to this article is available online at doi:10.5194/amt-8-463-2015-supplement.}

\section{Acknowledgements. Manus}

One of the upper air data sets developed for the Dynamics of the Madden-Julian Oscillation (DYNAMO) 2011 to 2012 project. This data set includes 1411 high vertical resolution (2s) soundings from the Atmospheric Radiation Measurement (ARM) C1 Momote. These data were provided by ARM and had preliminary quality control by NCAR/EOL. This L3 version of the data set has a correction by CSU. This station used Vaisala RS92-SGP radiosondes with GPS wind finding during the DYNAMO field campaign.

Data provided by NCAR/EOL under sponsorship of the National Science Foundation. http://data.eol.ucar.edu/. Dataset name: Manus ARM AMF Radiosonde L3 Data (ESC Format) [NCAR/EOL], http://data.eol.ucar.edu/codiac/dss/id=347.009.

\section{Southern Great Plains}

Data were obtained from the Atmospheric Radiation Measurement (ARM) Program sponsored by the US Department of Energy, Office of Science, Office of Biological and Environmental Research, Climate and Environmental Sciences Division.
Lindenberg

The 1999 to 2009 data is based on radiosonde measurements using Vaisala RS90 instruments.

The 2009 to 2012 data is a GRUAN data product (RS92-GDP V2) based on radiosonde measurements using Vaisala RS92 instruments. All GRUAN data products are based on measurements and processing that adheres to the GRUAN principles (Immler, 2010). The raw data are read from the original DigiCora III data base files and are corrected for known systematic biases. The uncertainty of the temperature, the humidity and the wind is calculated from estimates of the calibration uncertainty, the uncertainty of the bias correction and the statistical noise.

Data provided by German Meteorological Service (DWD).

Edited by: B. Kahn

\section{References}

Free, M. and Seidel, D.: Causes of differing temperature trends in radiosonde upper air data sets, J. Geophys. Res., 110, D07101, doi:10.1029/2004JD005481, 2005.

Immler, F. J., Dykema, J., Gardiner, T., Whiteman, D. N., Thorne, P. W., and Vömel, H.: Reference Quality Upper-Air Measurements: guidance for developing GRUAN data products, Atmos. Meas. Tech., 3, 1217-1231, doi:10.5194/amt-3-1217-2010, 2010.

Mo, T.: Prelaunch calibration of the Advanced Microwave Sounding Unit-A for NOAA-K, IEEE T. Microw. Theory, 44, 14601469, doi:10.1109/22.536029, 1996.

Randel, W. J., Shine, K. P., Austin, J., Barnett, J., Claud, C., Gillett, N. P., Keckhut, P., Langematz, U., Lin, R., Long, C., Mears, C., Miller, A., Nash, J., Seidel, D. J., Thompson, D. W. J., Wu, F., and Yoden, S.: An update of observed stratospheric temperature trends, J. Geophys. Res., 114, D02107, doi:10.1029/2008JD010421, 2009.

Seidel, D. J. and Free, M.: Measurement requirements for climate monitoring of upper air temperature derived from reanalysis data, J. Climate, 19, 854-871, 2006.

Sun, B., Reale, A., Seidel, D. J., and Hunt, D. C.: Comparing radiosonde and COSMIC atmospheric profile data to quantify differences among radiosonde types and the imperfect collocation on comparison statistics, J. Geophys. Res., 115, D23104, doi:10.1029/2010JD014457, 2010.

Thorne, P., Voemel, H., Bodeker, G., Sommer, M., Apituley, A., Berger, F., Bojinski, S., Braathen, G., Calpini, B., Demoz, B., Diamond, H. J., Dykema, J., Fasso, A., Fujiwara, M., Gardiner, T., Hurst, D., Leblanc, T., Madonna, F., Merlone, A., Mikalsen, A., Miller, C. D., Reale, T., Rannat, K., Richter, C., Seidel, D. J., Shiotani, M., Sisterson, D., Tan, D. G. H., Vose, R. S., Voyles, J., Wang, J., Whiteman, D. H., and Williams, S.: GCOS reference upper air network (GRUAN): steps towards assuring future climate records, AIP Conf. Proc., 1552, 1042, doi:10.1063/1.4821421, 2013.

von Clarmann, T.: Validation of remotely sensed profiles of atmospheric state variables: strategies and terminology, Atmos. Chem. Phys., 6, 4311-4320, doi:10.5194/acp-6-4311-2006, 2006. 
WMO: The GCOS Reference Upper-Air Network (GRUAN) Guide, WIGOS Technical Report No. 2013-03, GCOS-171, 2013.

Zou, C. Z. and Wang, W.: Stability of the MSU derived atmospheric trend, J. Atmos. Ocean. Tech., 27, 1960-1971, doi:10.1175/2009JTECHA1333.1, 2010.
Zou, X., Lin, L., and Weng, F.: Absolute calibration of ATMS upper level temperature sounding channels using GPS RO observations, IEEE T. Geosci. Remote, 52, 1397-1406, doi:10.1109/TGRS.2013.2250981, 2014. 